\title{
Comunicación
}

\section{VALORES DE UREA Y CREATININA SÉRICA EN AÑUJES (Dasyprocta fuliginosa) DE UN ZOOLÓGICO DE LIMA}

\author{
Serum Values of Urea And Creatinine in Agoutis (Dasyprocta fuliginosa) \\ RAISED IN A ZOO IN LIMA
}

Gonzalo Campos N. ${ }^{1}$, Olga Li E. ${ }^{1,2}$, Patricia Ríos M. ${ }^{3}$, Walter Silva S. ${ }^{4}$

\section{ResUMen}

\begin{abstract}
El objetivo del presente estudio fue hallar los valores séricos de urea y creatinina en añujes (Dasyprocta fuliginosa) saludables criados en un zoológico de Lima. Se colectaron muestras de sangre de 23 añujes. El suero se separó por centrifugación y los valores de urea y creatinina sérica se determinaron mediante métodos colorimétricos con kits comerciales. El valor promedio de urea fue de $11.47 \pm 1.72 \mathrm{mg} / \mathrm{dl}$ y de creatinina de $2.41 \pm$ $1.06 \mathrm{mg} / \mathrm{dl}$. No se encontró diferencia estadística entre sexos ni edades.
\end{abstract}

Palabras clave: añuje, Dasyprocta fuliginosa, cautiverio, urea, creatinina

\section{Abstract}

The aim of the study was to establish values for urea and creatinine in serum from 23 healthy Black Agouti (Dasyprocta fuliginosa) kept in captivity in a Zoo in Lima. The sera were harvested after centrifugation and levels of urea and creatinine determined by colorimetric methods using diagnostic commercial kits. The mean value of urea was 11.47 $\pm 1.72 \mathrm{mg} / \mathrm{dl}$ and for creatinine was $2.41 \pm 1.06 \mathrm{mg} / \mathrm{dl}$. None statistical difference was found due to sex or age.

Key words: black agouti, Dasyprocta fuliginosa, captivity, urea, creatinine

\footnotetext{
${ }^{1}$ Laboratorio de Patología Clínica y Biología Molecular, ${ }^{3}$ Laboratorio de Anatomía Animal y Vida Silvestre, Facultad de Medicina Veterinaria, Universidad Nacional Mayor de San Marcos, Lima

${ }^{2}$ E-mail: olgalie@hotmail.com

${ }^{4}$ Instituto Nacional de Salud, Lima
} 
El uso de recursos biológicos es una de las bases de la alimentación de las poblaciones amazónicas (Brack Egg, 2000), lo que trae como consecuencia que las poblaciones de animales silvestres se vean afectadas por la presión de caza y por la reducción del hábitat (Valqui y Bodmer, 1997). Parte de la fauna silvestre de la Amazonía podría ser manejada en forma apropiada, como se viene haciendo en otras latitudes, a través de programas de manejo y uso adecuados (Fang et al., 1997).

El manejo de fauna silvestre en cautiverio, por otro lado, demanda un programa sanitario apropiado. Para esto, se requiere disponer, entre otros componentes, de valores fisiológicos de referencia (temperatura corporal, frecuencia cardiaca y respiratoria, bioquímica sanguínea, hematología, etc.) de las especies en cautiverio, a fin de poder compararlos con los valores encontrados durante los exámenes clínicos y de laboratorio, y así determinar el estado de salud del individuo o la población.

El añuje (Dasyprocta fuliginosa) es una especie que viene siendo criada en cautiverio con fines comerciales. La función renal de estos animales puede ser afectada por una amplia variedad de factores, y de esa manera alterando los niveles séricos de urea o creatinina (Sodikoff, 1996). El objetivo del presente estudio fue medir las concentraciones de estas sustancias con el fin de tener valores referenciales para la evaluación del grado de insuficiencia renal (Guyton, 1997).

El estudio se llevó a cabo en el zoológico Patronato Parque de las Leyendas (PATPAL), ubicado en el distrito de San Miguel, Lima, y el procesamiento de las muestras se realizó en el Laboratorio de Patología Clínica de la Facultad de Medicina Veterinaria de la Universidad Nacional Mayor de San Marcos, Lima.

Se recolectó sangre a los 23 añujes del PATPAL (11 machos y 12 hembras), los cua- les se hallaban mantenidos bajo similares condiciones de sanidad y manejo. Se atrapó a los animales con materiales de captura. La contención química se hizo mediante el uso de $10 \mathrm{mg} / \mathrm{kg}$ de ketamina y $1 \mathrm{mg} / \mathrm{kg}$ de xilacina (Carpenter, 1996), vía i.m, la cual produjo la sedación e inmovilización de los animales por 10 a 20 minutos. Se hizo un examen clínico a cada animal y se colectó una muestra de 3 $\mathrm{ml}$ de sangre de la vena femoral.

Las muestras se dejaron en reposo por dos horas y luego se centrifugaron para separar el suero. Se determinó los niveles de urea y creatinina mediante kits colorimétricos comerciales. La lectura de la absorbancia se realizó con un espectrofotómetro UV (Photometro 4010 Manheim Boehringer), con una longitud de onda de $540 \mathrm{~nm}$. Para el análisis de los datos se utilizó la media aritmética como medida de tendencia central (Daniel, 1996), y como indicador de incertidumbre se utilizó el intervalo de confianza.

Los valores promedio e intervalos de confianza de urea y creatinina se muestran en el Cuadro 1. El valor promedio de urea fue de $11.47 \pm 1.72 \mathrm{mg} / \mathrm{dl}$; valor inferior al de $19.04 \mathrm{mg} / \mathrm{dl}$ en Dasyprocta leporina (ISI, 1999). Esta diferencia, aparte de la especie, podría atribuirse a una dieta baja en proteínas (básicamente de verduras) utilizada en el PATPAL, ya que la urea es un producto final del metabolismo de las proteínas en el hígado (Benjamín, 1991).

Cuadro 1.Valores de urea y creatinina sérica de 23 añujes mantenidos en cautiverio en el Zoológico del PATPAL (2004)

\begin{tabular}{lcc}
\hline & Promedio & $\mathrm{IC}^{1}$ \\
\hline $\begin{array}{l}\text { Urea } \\
(\mathrm{mg} / \mathrm{dl})\end{array}$ & 11.47 & $9.75-13.19$ \\
$\begin{array}{l}\text { Creatinina } \\
(\mathrm{mg} / \mathrm{dl})\end{array}$ & 2.41 & $1.35-3.47$ \\
\hline${ }^{1}$ Intervalo de confianza del 95\% &
\end{tabular}


El valor de creatinina fue de $2.41 \pm 1.06$ $\mathrm{mg} / \mathrm{dl}$, superior al valor de $0.99 \mathrm{mg} / \mathrm{dl}$ reportado por ISIS (1999) en Dasyprocta leporina. El ejercicio de los animales ocasionado durante la captura de los animales podría haber elevado los valores de creatinina, toda vez que este compuesto interviene en la resíntesis de ATP ante esfuerzos de origen anaeróbico, de elevada intensidad y corta duración (Benjamín, 1991).

Los valores promedio de urea para machos y hembras fueron de 10.90 y $12 \mathrm{mg} / \mathrm{dl}$, respectivamente, en tanto que los valores de creatinina para machos y hembras fueron de 2.45 y $2.46 \mathrm{mg} / \mathrm{dl}$, respectivamente, sin encontrarse diferencias estadísticas entre sexos.

\section{Literatura Citada}

1. Benjamín M. 1991. Manual de patología clínica en veterinaria. $3^{\mathrm{a}}$ ed. México: Ed. Limusa. 421 p.

2. Brack Egg A. 2000. Biodiversidad amazónica y manejo de fauna silvestre. En: Manejo de fauna silvestre en la amazonía. La Paz, Bolivia: Ed Instituto de Ecología. p 3-14.
3. Carpenter J. 1996. Exotic animal formulary. $2^{\text {nd }}$ ed. Pennsylvania, USA: WB Saunders. 540 p.

4. Daniel W. 1996. Bioestadística, base para el análisis de las ciencias de la salud. $3^{\mathrm{a}}$ ed. México: Ed Limusa. 915 p.

5. Fang T, Bodmer R, Aquino R, Valqui $M$. 1997. Manejo de fauna silvestre en la Amazonía. La Paz, Bolivia: Ed Instituto de Ecología. 334 p.

6. Guyton A. 1997. Tratado de fisiología médica. $9^{a}$ ed. México: Interamericana McGraw-Hill. 1262 p.

7. [ISIS] International Species Information System. 1999. Clinical pathology records report. ISIS/ In house reference values mammals. [Internet]. Disponible en: htpp:/ www.worldzoo.org

8. Valqui M, Bodmer R. 1997. Uso de los Proechimys spp. como fuente de proteínas en la selva baja del Perú: una alternativa a la caza no sostenible de primates. En: Manejo de fauna silvestre de la amazonía. La Paz, Bolivia: Ed Instituto de Ecología. p 319-327.

9. Sodikoff C. 1996. Pruebas diagnósticas y de laboratorio en las enfermedades de pequeños animales. $2^{\mathrm{a}}$ ed. Madrid: Ed Mosby. 435 p. 